\title{
La merced despoblada. Tenencia y derechos de propiedad en las tierras de Maíz Gordo y Santa Bárbara (Jujuy, Argentina), 1850 a 1920/
}

\author{
The Deserted Merced. Possesion and Duty of Properties \\ in Maiz Gordo and Santa Barbara (Jujuy, Argentina), \\ from 1850 to 1910
}

\author{
Cecilia A. Fandos \\ ORCID iD: http://orcid.org/0000-0003-2699-7913 \\ CONICET (ISHIR/UNIHR/UNJu)
}

Centrado en los procesos de constitución de la tierra pública en la Argentina decimonónica este artículo aborda un caso particular -Maíz Gordo y Santa Bárbara (provincia de Jujuy)_, donde obró un fenómeno de fiscalización por desconocimiento de derechos privados debido al carácter de «merced despoblada». Nos proponemos indagar las formas y evolución de los derechos de propiedad durante todo este suceso teniendo en cuenta, por una parte, a los actores expropiados y a los nuevos propietarios y, por otra parte, a los sujetos que efectivamente las poblaban (puesteros, ocupantes de hecho, arrendatarios).

Palabras Clave: Derechos de propiedad; Actores sociales; Propiedad fiscal.

Based on the processes of constitution of public land in the 19th century in Argentina, this article is focused in the particular case of Maiz Gordo y Santa Bárbara (province of Jujuy), where a special phenomenon of the state control occured due to ignore the private rights of a land that was supposed to be deserted. We intend to investigate the different forms and evolution of property rights during this whole event, considering, on the one hand, the expropriated actors and the new owners, and on the other hand, the people who effectively populated them (tenants, ocuppants of fact, etc.).

KEYwORDs: Propery's duty; Social actors; Fiscal propery.

Copyright: (C) 2017 CSIC. Este es un artículo de acceso abierto distribuido bajo los términos de una licencia de uso y distribución Creative Commons Attribution (CC-by) España 3.0. 


\section{Introducción}

Durante la constitución del Estado en la Argentina se fue forjando un importante patrimonio inmobiliario en sus distintas jurisdicciones -nacional y/o provincial-, sobre el que se sustentó un conjunto de ensayos distributivos de tierra, con variados corolarios socioeconómicos. En un estudio sobre las plataformas ideológicas de las políticas agrarias oficiales Míguez propone interesantes vinculaciones entre los proyectos de apropiación de la tierra pública y los de «reforma social». Encuentra que los principales preceptos conceptuales que guiaron el manejo de la propiedad fiscal en el Río de la Plata mantuvieron una línea de continuidad desde el siglo XVIII y hasta finalizado el siglo XIX — con la excepción del régimen rosista (1835-1852) —, que se entroncaba con la postura «agrarista» de los ilustrados borbónicos, ${ }^{1}$ primero, y con el patrón norteamericano de Thomas Jefferson, luego. En su diálogo con las tradiciones historiográficas sobre el asunto, sin embargo, el autor deja claro que hubo una notable distancia entre proyectos y realidad, principalmente porque en la definición de los derechos de propiedad intervinieron una serie de factores que van más allá de las instituciones creadas al efecto, como la disponibilidad de los recursos, las prácticas preexistentes, «la mentalidad de los actores, la oferta de los factores y la evolución de los acontecimientos». ${ }^{2}$

La incorporación de una pluralidad de fuentes alternativas a la legislación en materia de tierras públicas ${ }^{3}$ ha permitido complejizar el conocimiento sobre su origen, formas de apropiación y transferencia, las tramas sociales que subyacían en estos espacios agrarios colmados de diferentes actores, y también por la multiplicación de escalas geográficas regionales y microregionales que se analizan. ${ }^{4}$ Así, una lista amplia y muchas veces contrapuesta demuestra la gama de opciones que adoptaron las políticas oficiales pese a la matriz general liberal de consagrar la propiedad privada. Las distintas iniciativas obedecieron al carácter divergente de tierras de antigua ocupación o espacios de fronteras: ${ }^{5}$ distribución fraccionaria con

1 Comulgando con las ideas fisiocráticas y un modelo de pequeños propietarios y productores independientes, mediante la implementación de planes de colonización.

2 Míguez, 2007, 142-143.

3 Ese fue uno de los tópicos prevalecientes en los estudios pioneros sobre el tema como el de Cárcano, 1972.

4 No podemos aquí dejar planteado un catálogo completo de los numerosos aportes producidos, citamos como texto referencial la compilación de Blanco y Banzato, 2009.

5 La primera categoría alude a los territorios controlados estatalmente desde la etapa colonial donde el paquete de tierras públicas se generó por procesos de expropiación y desamortización de 
base en la pequeña propiedad, subastas públicas de grandes unidades territoriales al mejor postor como garantía de inmediatos y seguros ingresos estatales o de radicación de empresas «viables», cesión gratuita con finalidad política, entrega de tierra a naturales y pobladores originarios, proyectos de colonización para el asentamiento de inmigrantes, o como fomento a determinados rubros productivos para procurar concretos modelos de desarrollo e inserción en los mercados mundiales.

También en la provincia de Jujuy, situada en el extremo fronterizo del Noroeste argentino, convergieron diversos modelos constitutivos de la propiedad fiscal. Así, parte de ese dominio se situó en la Quebrada de Humahuaca y se instituyó desde fines de la década de 1830 como consecuencia de la desamortización y expropiación de la propiedad comunal incumbiendo a varios pueblos de indios de la región. ${ }^{6}$ Otro modo de conformación de bienes inmobiliarios públicos tuvo lugar en el territorio de la Puna en la década de 1870, donde igualmente se fraguaron sobre áreas de antigua ocupación y formas de dominio de raíz colonial, como sucedió con las tierras de Casabindo y Cochinoca. El hecho surgió de la acción de los pobladores indígenas arrendatarios que desconocieron los derechos de propiedad ejercidos entonces, concerniendo directamente a los intereses de uno de los principales encomenderos y terratenientes de la zona, el heredero de turno de los marqueses de Tojo, Fernando Campero. Estas tierras originariamente repartidas a los pueblos de indios de Casabindo y de Cochinoca (a su vez población afectada a la encomienda del marquesado de Tojo) pasaron definitivamente al dominio fiscal de Jujuy en 1877 por reversión del derecho real. ${ }^{7}$ En la causa judicial que se tramitó en la Corte Suprema de Justicia, cuya sentencia definitiva fue a favor del Estado provincial, se diferenciaron claramente las figuras coloniales de mercedes de encomienda con las de tierras, se declararon caducas las primeras y se determinó que las haciendas de Jujuy nacidas de las mercedes de tierras eran tenidas como propiedad privada con títulos válidos para el gobierno provincial. ${ }^{8}$

\footnotetext{
antiguos derechos de propiedad. Los «espacios vacíos» — aunque no lo fueron en términos realesfueron trazados sobre los territorios sin control estatal, por eso concebidos como «espacios de frontera», que paulatinamente desde finales del siglo XVIII y principalmente en el siglo XIX fueron incorporados a esa esfera y reconocidos inicialmente como propiedad fiscal.

6 Fandos y Teruel, 2013.

7 Madrazo, 1982.

8 Paz, 2004, 561. Con ese antecedente las causas legales que se sucedieron cuestionando la validez de títulos originados en mercedes de tierras fueron rechazados, si la merced de tierra resultaba probada era fuente de pleno reconocimiento de propiedad privada, Fandos, 2015.
} 
Asimismo, otro caso singular de formación de propiedad pública afectó a antiguas mercedes de tierras ubicadas en la zona de Maíz Gordo y de Santa Bárbara, donde operó el desconocimiento de derechos de propiedad por el carácter de «despueble». En este artículo repasamos todo el asunto corrido judicialmente hasta llegar a la declaratoria de tierra fiscal (1883) en esta geografía, y también las oscilantes políticas estatales para definir sobre ellas nuevos derechos, hasta comienzos de la década de 1920. Nuestro objetivo central es analizar el proceso histórico de formulación de ese dominio público y de definición de nuevos derechos de propiedad, a la vez de determinar los diseños de cesión y transmisión ensayados. Más allá de tener en cuenta a los actores expropiados y a los beneficiarios de las transferencias, nos proponemos también indagar las formas y evolución de tenencia de quienes sí las poblaban (puesteros, ocupantes de hecho, arrendatarios) durante ese proceso. Para ello nos basamos en una multiplicidad de fuentes, estadísticas y de contenido, que ponen en evidencia esa trama social subalterna a los propietarios. Sin enfocar aspectos más clásicos del tema como son la ecuación tierra pública-ingresos fiscales o el estudio exhaustivo del funcionamiento del mercado de tierras, apuntamos a desentrañar la singularidad del caso como un aporte al conocimiento más general de las políticas de tierras públicas en América latina, la formulación de derechos de propiedad en la era republicana liberal, las respuestas y los resultados en términos sociales.

\section{Maíz Gordo y Santa Bárbara, tierra de «frontera». De la merced a la expropiación}

Entre las condiciones geográficas de la provincia de Jujuy un factor de peso es la pluralidad ambiental que presenta. Efectivamente, sobre el extremo cordillerano se ubican las llamadas «tierras altas», conformadas por la Puna y la Quebrada de Humahuaca, compuestas por mesetas de altura -entre 3.000 y 4.000 metros sobre el nivel del mar-, y valles de altura entre los 600 y los 3.700 msnm. A su vez las «tierras bajas» presentan zonas de climas templados y terrenos a $1.200 \mathrm{msnm}$; por un lado, la región de los Valles Centrales que fue el territorio escogido para el emplazamiento de la principal ciudad cabecera en la jurisdicción al producirse la conquista de la zona; por otro lado, más hacia el oriente de la provincia, la región de los Valles Orientales fue el epicentro de la agroindustria azucarera a fines del siglo XIX (sello económico fundamental de la economía provincial). 
El espacio que nos interesa abordar es el actual departamento de Santa Bárbara (ver mapa), comprende el ambiente natural de «yungas», por su carácter de selva tropical y bosque andino, presenta un relieve montañoso y accidentado, una importante pluviosidad y red fluvial. Este territorio está emplazado en las postrimerías del «Impenetrable», en la región geográfica del Gran Chaco, ${ }^{9}$ nombre que alude a una agreste y tupida vegetación de un espacio natural que dificulta el acceso y fácil control humano.

Los intentos de ocupación española datan del siglo XVII, con una existencia efímera. El control comenzó a fraguarse durante el reinado de los Borbones, en el siglo XVIII, cuando algunas campañas militares resultaron exitosas y se pudo asegurar una línea defensiva con una cadena de fuertes. Ese sistema quedó reforzado con la implementación de estrategias «pacificadoras» fundando misiones o reducciones al mando de órdenes religiosas. ${ }^{10}$ En ese devenir se creó en 1765 el Fuerte de Santa Bárbara. Como demuestra Teruel, esa política de ocupación se completó, a su vez, con el reparto de tierras a particulares bajo la figura de mercedes reales, el acceso por compra de las propiedades misionales y por ocupaciones de hecho. El resultado social fue que los militares adelantados en las entradas al Chaco fueran los principales beneficiarios de las mercedes fortaleciendo la concentración de la propiedad y la constitución de grandes haciendas, como esencia del paisaje agrario. Pero, paralelamente, la frontera permeó el acceso a la tierra también a los soldados de menor rango a través de mercedes o por la propia radicación en el lugar, y a un conjunto de migrantes que si no alcanzaron la propiedad, pudieron asentarse como arrendatarios o simples ocupantes de hecho. ${ }^{11}$

El escenario original de las tierras de Santa Bárbara y Maíz Gordo comparte los rasgos generales de ese proceso. En efecto, la apropiación del territorio se hizo en base al otorgamiento de cinco mercedes: la de Robles, la de Iriarte, la de Zegada y las tierras de Lavayen. ${ }^{12}$ Cabe recalcar que lejos

9 Un área que involucra a las provincias argentinas de Salta, Formosa, Chaco y Santiago del Estero, y también porciones de Brasil, Paraguay y Bolivia.

10 Teruel, 2005, 31.

11 Ibidem, 34.

12 La primera fue cedida en 1760 al Comandante de los presidios de las fronteras Francisco Javier Robles. Diego Tomás Martínez de Iriarte fue beneficiario de la merced de otra porción en esta región (en 1765). A ellos se suma el nombre de Gregorio de Zegada quién se hizo merecedor en 1779 de otras tierras. Finalmente, en Lavayen se fraguaron derechos de propiedad por mercedes otorgadas en distintas épocas a dos sujetos diferentes: uno, la merced de Lavayen cedida a Agustín Martínez de Iriarte, en 1714; dos, la merced del Fuerte de Lavayen — con una extensión de ocho cuadras cuadradas, que fue parte de la política de poblamiento de esas fortalezas defensivas para asentar habitantes en los mismos— recayó en 1751 en favor de Juan Montero. Tello, 1889. 
de desconocerse la documentación aportada por los sucesores de ese reparto originario en el procedimiento seguido para delimitar la propiedad fiscal en la zona durante la segunda mitad del siglo XIX, el gobierno y los peritos actuantes no cuestionaron su validez. Es decir, como ya sucedía en otras áreas geográficas de Jujuy, la merced de tierra probada fue legitimada como propiedad privada. No obstante, desde el momento mismo de distribución de estas mercedes se suscitaron litigios entre los propietarios vecinos por la imprecisión de linderos, que resultaban deficientes y ambiguos. En ese haz de tensiones, por ser cesiones superpuestas, se mantuvo por casi un siglo la demarcación de las tierras de los Robles e Iriarte. ${ }^{13}$

La declaración de tierras fiscales, en la década de 1880, de amplias superficies territoriales del departamento de Santa Bárbara fue un proceso de larga gestación. La primera vacilación sobre el carácter fiscal se debe a una diligencia iniciada en la década de 1840, en la que se dio aviso de baldío a las autoridades, se hicieron las tareas de reconocimiento y la publicación de edictos. ${ }^{14}$ El siguiente turno fue entre 1861-1863, con tres denuncias sucesivas entabladas por Tomás Alvarado, provocando el reconocimiento definitivo del Potrero de Capichunco como propiedad de la provincia. ${ }^{15}$ Esta constituyó la primera zona de demarcación fiscal del departamento de Santa Bárbara. Entre los años 1863 y 1865 se implementó la ocupación de ellas por un sistema de arriendos, ${ }^{16}$ para luego privatizarlas por remate público.

Luego hubo otras dos instancias más, previas a la resolución adoptada en 1883. Una corrió entre 1876-80, con la imputación de terrenos baldíos a los situados en un punto reconocido como tierras del Este de la Totorilla. La denuncia fue introducida por dos vecinos de la zona y de inmediato el gobierno procedió a la convocatoria de interesados por edictos. En ese acto los herederos de la merced de Robles acusaron derechos, pero igualmente tras las tareas oficiales de inspección resultó fiscal.$^{17} \mathrm{El}$ trámite quedó avanzado hasta este punto de reconocer estas porciones del territorio del departamento de Santa Bárbara, sin terminar de concretarse

13 Efectivamente, el deslinde judicial definitivo de estos intereses contrapuestos se celebró en 1882, Tello, 1889, 45.

14 Nota al Gobierno, San Pedro, 2 de agosto de 1855, Archivo Histórico de la Provincia de Jujuy (AHJ), Caja de Documentos, año 1855.

15 Tello, 1889, pp. 96-98.

16 Nota de Romualdo Mora, Santa Bárbara, 15 de enero de 1864 y 19 de julio de 1863, AHJ, Caja de Documentos, año 1863.

17 Tello, 1889, 48. 
la declaración por la contención interpuesta por José Lozano (heredero de las tierras de Robles) atento a los términos del decreto del 3 de julio de 1874. Es interesante detenernos en los motivos históricos coyunturales que incidieron en esa circunstancia, pues esa norma restituía las tierras expropiadas en esa época en Casabindo y Cochinoca, y fue aprobada con fuerza de ley el 12 de marzo de $1875 .{ }^{18}$ La figura judicial que frenó la afirmación sobre el carácter fiscal de todas estas propiedades fue la incompetencia del poder ejecutivo para ese acto, que debía ser reservado para los tribunales de justicia por ser juicios contenciosos. Fue una respuesta frente a la abierta rebelión campesina indígena de la Puna jujeña desatada desde el año 1872. Los arrendatarios de las fincas de Casabindo y Cochinoca presentaron denuncia cuestionando la legitimidad de los títulos de propiedad de su patrón, Fernando Campero, acogida positivamente por el gobierno provincial, declarándolas fiscales en una primera instancia. Ese viso favorable a los sectores campesinos animó a pares de otras haciendas, agudizando la situación con acciones de violencia. En ese clima un nuevo gobierno de turno en 1874 lanzó el decreto que tratamos y otro en el que se restituyeron las tierras expropiadas a Campero. ${ }^{19}$

La otra pericia para declarar tierra pública en Santa Bárbara y Maíz Gordo introdujo, por primera vez, el despoblamiento de viejas mercedes como argumento de base, con dos sumarios administrativos iniciados en 1872. En estos casos no se puntualizaba un área geográfica específica, como se había hecho con Capichunco y Este de Totorilla, porque se entendía que cerca de una cuarta parte del territorio provincial se ajustaba a la situación de despueble, afectando «unas seis mil doscientas leguas cuadradas». ${ }^{20}$ La novedad de la tesis exigía otras tareas oficiales inéditas. Además de la ya usual publicación de edictos, era preciso levantar información testimonial entre todos los vecinos del lugar para comparecer sobre los tiempos de ocupación y reconocer a los dueños de las tierras. Según Tello así se procedió en el mes de abril del año 1872 trascendiendo que muchos lugares estaban despoblados. Luego de ello vino el decreto del poder ejecutivo declarando «baldías y de propiedad pública» las tierras de Maíz Gordo y parte de Santa Bárbara, el 31 de marzo de 1873. Sin embargo, el asunto no prosperó mucho más porque las cámaras legislativas no

18 Sesión ordinaria, San Salvador de Jujuy, 12 de marzo de 1875, Archivo Histórico de la Legislatura de Jujuy (AHLJ), Actas de Sesiones, Libro 13, f. 109.

19 Paz, 2004, 556.

20 Tello, 1889, 51. 
le dieron fuerza de ley, ni se actuó en consecuencia en la organización de una comisión de deslinde de las tierras comprometidas. Por el contrario, se devolvió el expediente al poder ejecutivo el 23 de marzo de 1875, sin ninguna resolución al respecto. ${ }^{21}$

Estos hechos administrativos eran coetáneos de la convulsión social y política que derramaba el levantamiento campesino en la Puna de Jujuy. Nuevamente, el decreto de incompetencia administrativa del gobierno provincial para entender en ciertos actos de denuncia de tierras fiscales de julio de 1874, que ya tratamos, frenó jurídicamente este proyecto de fiscalización en Santa Bárbara. ${ }^{22}$ Además contribuyeron a este estado de cosas la oposición de los propietarios damnificados, José Lozano y herederos de Martínez de Iriarte, siendo que para finales del año 1882 el juez sentenció como extinguida esa causa. Pero el asunto se retomó oficialmente un año después, lográndose entonces contar con la sanción de ley de tierras fiscales de Maíz Gordo y Santa Bárbara, el 13 de diciembre de 1883.

\section{Fundamentos de la ley de fiscalización de 1883. ¿Qué tierras son fiscales y cuáles son privadas en Santa Bárbara?}

El instante político, el sello de un nombre propio y la coyuntura histórica rebaten cualquier rasgo de contingencia a la sanción de esta ley. Por el contrario, el momento expresa un punto culminante del recorrido transitado en la consolidación de los derechos de propiedad privada en Jujuy. Ese estadio estuvo encarnado en la figura del gobernador de turno Eugenio Tello (1883-1885), a quien se puede considerar como uno de los máximos exponentes provincianos del «orden burgués» vinculado al tejido político del «roquismo» en la Argentina. ${ }^{23}$ Fue entonces cuando de las reformas iniciadas previamente con la desamortización de la propiedad y la expropiación de terrenos comunales que habían reportado a las primeras tierras fiscales, se pasó a la etapa del ordenamiento y de la legitimación de la propiedad privada con un plan de acción gubernamental múltiple: subdivisión de latifundios improductivos, erradicación de las tendencias de propiedad comunal afianzando al campesino como propietario privado por compra-venta,

21 Sesión ordinaria, San Salvador de Jujuy, 23 de marzo de 1875, AHLJ, Actas de Sesiones, Libro 13, fs. 130-132.

22 Tello, 1889, 56

23 Teruel y Bovi, 2010. 
incentivo a la colonización e inmigración mediante entrega gratuita de tierras y autonomía de los pueblos nucleados en las haciendas azucareras. ${ }^{24}$

En ese contexto, la ley del 13 de diciembre de 1883 declaraba explícitamente fiscales las del Este de la Totorilla y las existentes en Maíz Gordo y Santa Bárbara, ordenaba practicar un inmediato deslinde y su venta posterior con preferencia de los actuales ocupantes, paralelamente reservaba unas 50 leguas cuadradas para la colonización oficial y promovía la inversión de capitales externos autorizando cesiones gratuitas a los sujetos interesados en ese propósito. Además, conceptuaba explícitamente el despueble, del que se valía el reconocimiento fiscal, como «terrenos de más de tres leguas de extensión en las que no hayan ganados, casas, [...] o algún otro trabajo hecho que indique ocupación actual». ${ }^{25}$

Tello, en su informe de 1889, delibera sobre el siguiente asunto: «¿Por qué el gobierno provincial consideró fiscales aquellas estancias despobladas? Porque toda merced de tierras se concedía por los agentes del rey de España para poblarlas».$^{26} \mathrm{La}$ idea madre se fundaba en las leyes castellanas del siglo XV que figuraban el carácter gracioso, revocable y de orden público que revestían las mercedes de tierras. También acude a las Leyes de Indias en referencia a la dimensión máxima de las estancias entregadas en merced (con una superficie de tres leguas cuadradas). ${ }^{27}$ Esta cuestión - tamaño de las mercedes - fue primordial para asentar la regla oficial de que no era necesario que la totalidad del área comprendida en cada una de las mercedes otorgadas en Santa Bárbara evidencie despoblamiento para fundar el derecho de propiedad fiscal, sino que bastaba con comprobar esa situación en ciertas «partes del todo». Así razonaba sobre el principio de que dominio y posesión eran jurídicamente distintas cosas y daba cabida a la posibilidad de divisibilidad de la propiedad integral: «en una merced de tierras tan extensa como las hechas a Robles e Iriarte, se comprendían muchas estancias, que hoy pasan de setenta, y por consiguiente estaban en el deber de poblarlas todas, lo que no ha sucedido en ciento veinte ocho años». ${ }^{28}$

El tema es interesante no solo por la interpretación jurídica sino también por el hecho de que la fiscalización obrada no abarcó todas las tierras

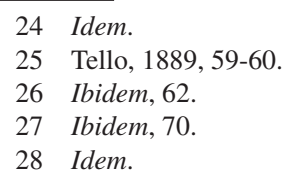


del actual departamento de Santa Bárbara sino partes que reunían determinadas condiciones:

1. Terrenos poseídos sin legítimos títulos de propiedad.

2. Terrenos despoblados actualmente

3. Terrenos poblados después de 1850 por sus propietarios o a nombre de ellos.

4. Terrenos cuyos pobladores no han reconocido derechos sobre los mismos, sino al fisco antes del 31 de diciembre de 1883 y continúan como tales. ${ }^{29}$

Tales parámetros solo podían ser eficaces luego de un meticuloso estudio de los antecedentes de cada palmo de tierra, misión que se encomendó a Nicolás Alvarado y se llevó a cabo entre los años 1884 y 1885. La inspección oficial se practicó en todo el espacio que originalmente comprendía las mercedes de los Robles e Iriarte y las del Este de la Totorilla, consistió en la fijación de lindes de estas propiedades y la determinación de lo que era fiscal y no fiscal, con un minucioso trabajo de campo y recopilación de toda prueba documental aportada por los interesados, se recorrió los terrenos y se tomó declaración a los pobladores y propietarios. Con los resultados de este deslinde hemos elaborado la tabla que adjuntamos en el anexo y que analizamos a continuación.

El acto oficial de deslinde y de mensura diseñó una variedad de derechos siendo posible distinguirse las tierras fiscales, las de propiedad privada y un conjunto que se consideraron inciertas. $\mathrm{Al}$ menos es posible reconocer once escenarios diferentes como consecuencia del procedimiento efectuado.

Sin ser territorios despoblados ni desconocidos, la zona de Lavayen (ver mapa, zona 1) se reportó fiscal pese a la pretensión de propiedad privada, tanto de los herederos de las mercedes de los Iriarte como de los Monteros. En el examen de los límites se entendió que no comprometía la propiedad los Iriarte y, a su vez, los derechos de los Monteros fueron desconocidos porque no lograron exhibir títulos legítimos. Ambas familias para esa época habían celebrado contratos de compraventa, en calidad de propietarios, de por lo menos 10 fracciones, a cuyos nuevos titulares el Estado solo reconoció como simples poseedores. Posteriormente, el Estado admitió todas las pretensiones particulares resolviendo a favor de la propiedad privada en Lavayen.

Las tierras del Este de Totorilla (mapa, zona 2) también se consideraron fiscales, parte de ellas ya estaban privatizadas hacia la década de 1880 dado que reportaban ese carácter desde 1876. Ahora se sumaron al paquete público otras secciones que estaban sin poblar y fuera de las fronteras de

29 Alvarado, 1886, 171. 
las propiedades circundantes de los Zegada. Una situación semejante, fiscal desde los años sesenta y vendidas luego, resultó en el potrero de Capichunco (mapa, zona 3), en la región que alcanzaba el trazado de la merced de Robles hacia el sur.

Dentro de los bordes oriental y norte de la merced de Robles (mapa, zona 4) se localizaron áreas comprendidas en la misma, que en el criterio oficial no habían sido transferidas con el grueso de este patrimonio en la operación de ventas de los herederos de Robles a Mariano Gordaliza, en 1813. Por esa clarificación de linderos efectuados en la mensura de Alvarado quedaron fijadas una serie de parcelas fiscales que se encontraban despobladas, y las que presentaban títulos insuficientes, desechándose los derechos particulares de las fincas del Quemado, Gramillar y Palmar de los sujetos que las habían comprado a José Lozano (heredero en sucesión por la vía de los Gordaliza de las originales tierras de los Robles), para inscribirlos solo como poseedores.

Sobre el mismo dominio de Robles, hacia el lado occidental (mapa, zona 5), también se declaró pública una rica porción de ese territorio al ser catalogado entre los casos vinculados a límites imprecisos, y a la falta de títulos válidos de los poseedores de turno (aceptados oficialmente solo en ese estatus): la familia Villar, que alegaba derechos privados por ser sucesores de las tierras dadas en merced a Gregorio Zegada. Para el fisco esa merced resultaba superpuesta con la de Robles, que había sido otorgada primero pero que ahora tampoco presentaba mejor derecho por la condición de despueble.

Una parte importante de otra de las mercedes coloniales, la de los Iriarte, ubicada en la zona 6 del mapa, igualmente se sentenció fiscal. Como la familia Gil presentó una escritura de compra-venta, algunas fracciones del área quedaron sujetas a resolución para excluirlas de las propiedades públicas, pero se delimitaron zonas despobladas a las partes sobrantes de los Gil. Tres áreas más (zonas 7, 8 y 9 del mapa) no tuvieron definición en ese momento ya sea porque no se pudo cerrar el trámite de comprobación de pruebas presentadas, o porque los propietarios directamente no se presentaron al proceso de deslinde (algunos por ser vecinos de la provincia de Salta). Finalmente, había una región que no tenía muestras de incursión humana, se trataba de las tierras recostadas sobre la sierra de Maíz Gordo, extremo sur este de Santa Bárbara (zona 10 del mapa), que por inexploradas y despobladas también engrosaron las propiedades fiscales.

Hasta acá las tierras recorridas y clasificadas como privadas o públicas excluyen uno de los mayores patrimonios territoriales de Santa Bárbara durante el proceso de fiscalización: el de José Lozano, que abarcaba partes 
originarias de la merced de Robles, vendidas a Gordaliza en 1813. En esa porción hemos clasificado cuatro realidades diferentes. Como se ve (zona $11 \mathrm{~A}$ del mapa) un segmento importante no fue expropiado por el fisco, se reconoció como propiedad de Lozano y a cada uno de sus ocupantes como arrendatarios de aquel. También preservaron la condición de propiedad privada (zona 11B del mapa) tierras que Lozano había vendido pasada la mitad del siglo. Pero en un radio cercano a las 40.000 hectáreas de este contorno patrimonial que detentaba Lozano fueron declaradas fiscales por ser despobladas y ocupadas con posterioridad al año 1850 (tope seguido como primera declaración de baldías) (zona 11C del mapa). En su mayor parte estaban usufructuadas por un grupo de ocupantes de hecho que no pagaban renta a nadie y en algunas fracciones alegaban derecho privado de Salvador Villar y Lucas Gil.

Finalmente, la provincia encontró ciertas vacilaciones para declarar la condición de propiedad sobre otra zona (mapa, zona11D), pese a que sus ocupantes y puesteros desconocieron derechos de propiedad de Lozano en ese área (prueba suficiente en otros casos). Nicolás Alvarado, agrimensor encargado del deslinde de 1885, precisó una circunstancia peculiar en el dominio y posesión ejercido por la familia de Gordaliza para poner en tela de juicio si era el caso de terrenos despoblados estos que habían sido ocupados ilegítimamente. Narró la trama familiar a la muerte de su titular, don Mariano, seguida rápidamente por la de su esposa, de tal suerte que ese patrimonio quedó en manos de menores hasta que se pudieron hacer cargo. En ese lapso de tiempo, el ganado y la propiedad de Gordaliza fueron saqueados y apropiados por administradores, puesteros y arrendatarios. Todas estas consideraciones son explicitadas por Alvarado para asegurar, según su criterio, que no se puede interpretar la ley del 18 de diciembre de 1883, sobre «terrenos poblados por su dueño, despobladas luego [...] y pobladas últimamente por cualquiera que dijera "yo no sé de quiénes son y no pago arriendo a nadie [...]" Y si la causa de despoblación fue inevitable, fortuita ¿pueden así mismo ser fiscales?». ${ }^{30}$

Esta fue una cuestión que quedó irresuelta y que le restó el suficiente apoyo político para que el laborioso deslinde de Nicolás Alvarado quedara sin aprobación legislativa. En la práctica se estableció como referencia obligada de la primera exploración sistemática de la propiedad en Santa Bárbara a la hora de dirimir diversos conflictos. Como resultado de esta acción

30 Alvarado, 1886, 188. 


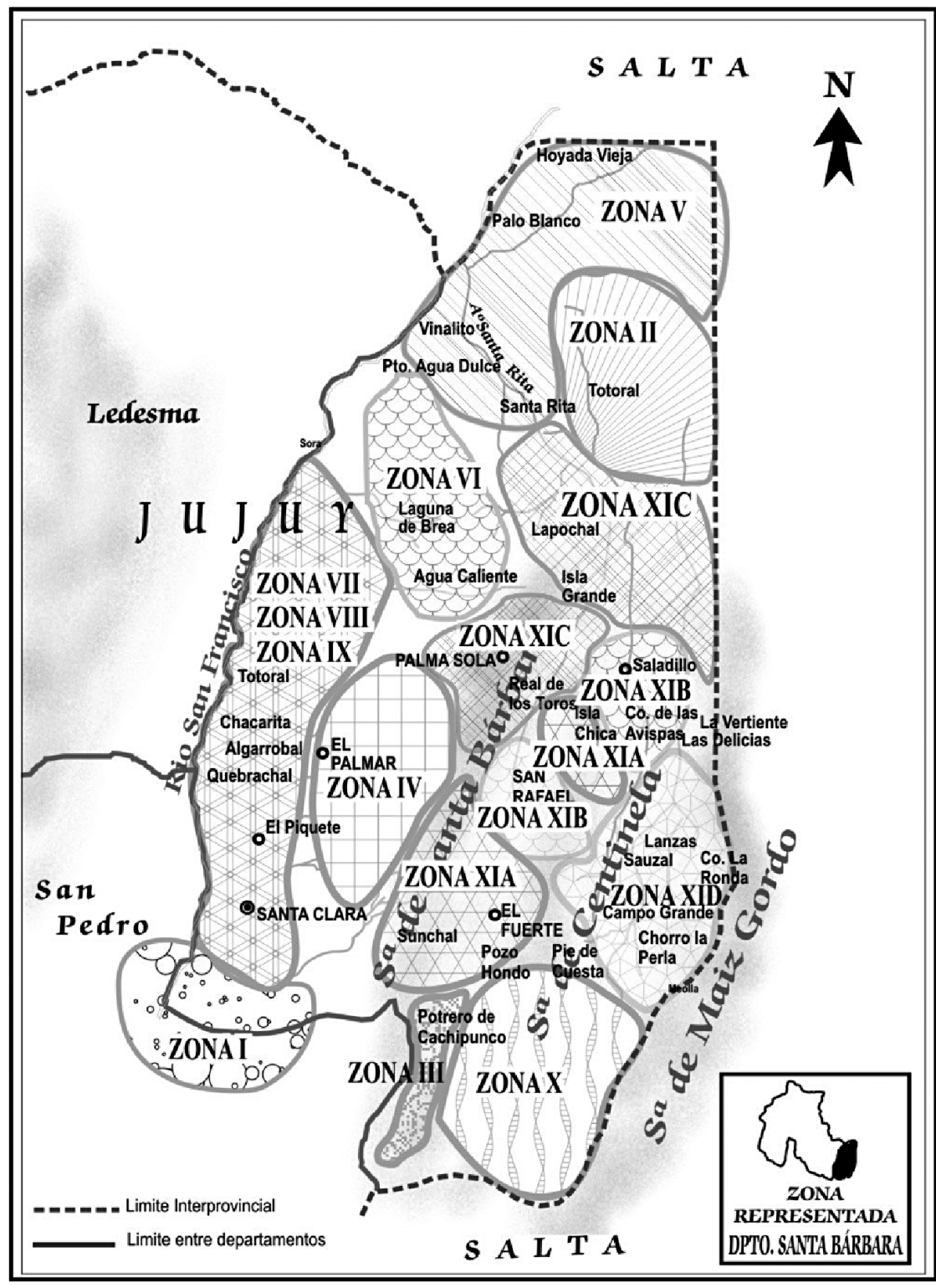

Fuente: Elaboración propia sobre la base de Alvarado (1886) y Cuestiones de Límites (1950). 
de 1885 podían considerarse fiscales unas 148 leguas cuadradas (más de 370.000 hectáreas), las que debían dividirse en cien lotes de agricultura de cien hectáreas cada uno y 46 lotes de estancia de dos a cuatro leguas cuadradas cada uno, implicando un haber público de 64.375 pesos. $^{31}$

\section{Una maraña de derechos I. Nuevos y viejos propietarios.}

Las tierras fiscales efectivamente controladas por el gobierno de la provincia de Jujuy fueron menores a las 370.000 hectáreas sumadas originalmente en el deslinde de Alvarado. Una de las más ricas por sus condiciones ambientales, aptas para cultivos tropicales en gran escala y la explotación forestal de sus frondosos bosques de quebracho, era Lavayen. Sin embargo, en sucesivas resoluciones gubernativas de finales de los años de 1880 se fueron certificando varias propiedades privadas y títulos de la zona, al punto de declarase a toda la región de Lavayen no fiscal, ${ }^{32}$ mutilando casi un $20 \%$ de la superficie estimada como tierra pública. ${ }^{33}$ La hilera de fincas recostadas en la margen derecha del río San Francisco (Santa Clara, Piquete, Quebrachal, Lecheronal, Chacaritas y Totoral, ubicadas de sur a norte), que en el deslinde de 1885 quedaron sin precisar, también fueron reconocidas como propiedades privadas. ${ }^{34}$

Frente la necesidad de sacar a la venta en remate propiedades de la región ${ }^{35}$ se realizó un nuevo deslinde y mensura general y pública (en paralelo corrían iguales trámites entre particulares de fincas vecinas), entre los años 1906-1907, que estuvo a cargo del ingeniero Ernesto Leonardi Cattólica. Si bien no hemos podido encontrar los registros de esta nueva mensura, sabemos que fueron aprobados y que desde entonces sirvieron en los siguientes procesos de deslinde. Con esa nueva base hubo reajustes desventajosos para

31 Ibidem, 201.

32 Tello, 1889, p. 151.

33 En el deslinde de Alvarado las tierras de Lavayen reconocidas fiscales eran 36 leguas cuadradas de cinco kilómetro cada legua (Alvarado, 1886, p. 193). Además, esos recortes del control público sobre esta región obedecieron a las marcaciones jurisdiccionales de hecho y de derecho que la provincia de Salta comenzó a ejercer desde el año 1894, provocando que esa zona sea un área de litigio entre ambas provincias. Cuestiones de Limites, 1950, 172.

34 Ya en el informe de Tello producido cuatro años después del deslinde no se encuentran inventariadas como tierras fiscales, ni en ningún otro plano de demarcación de tierras públicas levantado con posterioridad.

35 Ley 103, San Salvador de Jujuy, 18 de diciembre de 1905, AHJ, Registro Oficial, año 1905, f. 433 . 
el fisco en las delimitaciones con los inmuebles privados. De hecho, la superficie estimada entonces de tierra fiscal se redujo a más de la mitad de la calculada en la década de 1880 , ahora con 182.986 hectáreas. ${ }^{36}$

También se clarificaron los derechos que tenían los herederos de la merced de Gregorio Zegada considerados simples poseedores en 1885, ahora se asentó el carácter privado de las propiedades de José y Macedonio Villar sobre todo el cuadrante norte del departamento Santa Bárbara, desde Vinalito en esa dirección, conocido como El Palmar. ${ }^{37}$

Por otra parte, los desacuerdos surgidos con los dueños de algunas tierras luego de la fiscalización no fueron menores e impidieron el goce de la propiedad «plena y absoluta» que tanto se pregonaba, tanto del Estado como de los particulares. En este sentido, la situación más enredada fue la entablada entre Tomás Roque Alvarado y el gobierno de la provincia de Jujuy. La secuencia de este asunto es compleja y encubre una trama de conflictos cruzados, no solo por los entretelones socioeconómicos sino también de orden político. ${ }^{38}$

En 1880 Tomás Alvarado compró a José Lozano las propiedades de Pie de la Cuesta y Campo Grande (zona 11D del mapa). Esta propiedad le fue reconocida en absoluto dominio recién en 1906. En ese lapso de tiempo se disputaron, en primer lugar, las pretensiones fiscales sobre esas fracciones con las de Alvarado, pues en el deslinde de 1885 habían quedado sin determinarse en su condición de pública o privada. Esa indefinición paralizó la cuestión ya que el gobierno se declaró inhibido e incompetente para sentenciar al respecto - aludiendo nuevamente al decreto de julio de 1874-y, a la vez, tampoco reconoció los supuestos derechos de Tomás Alvarado. Por su parte, este reclamó recurrentemente al fisco se expida declaración sobre el carácter público o no de estas tierras, protestó su propiedad y denunció la inconstitucionalidad de la ley de 1883 que declaraba tierra fiscal a Santa Bárbara y Maíz Gordo. ${ }^{39}$ En segundo lugar, en las propiedades de

36 Cuestiones de Límites Interprovinciales, 1950, 271.

37 Ley 447, San Salvador de Jujuy, 27 de agosto de 1920, AHJ, Registro Oficial, tomo XXII, año 1920 , f. 452 .

38 En este trabajo nos abocamos simplemente a la primera dimensión, pero resaltamos que en todo el problema debió haber una trama política que no fue menor.

39 La ley era inconstitucional principalmente porque el decreto del «3 de julio de 1874 [...] resolvió que quedaba sin efecto todas las resoluciones y medidas que se hayan dictado administrativamente por los anteriores gobernadores contra los derechos de propiedad y posesión alegados por un ciudadano en contestación con el fisco». Pie de la Cuesta y Campo Grande, San Salvador de Jujuy, 18 de julio de 1890, AHJ, Caja de Documentos, año 1890, expte. 120A, foja rota. 
Pie de la Cuesta y Campo Grande también se superponían los intereses de Delfina Alvarado, quien aludía derechos de prescripción por posesión de treinta años.

La insistencia de Tomás Alvarado presionando una y otra vez al gobierno para que diera una definición clara al respecto desde 1884 fue el motivo que fundó el estudio de antecedentes efectuado por Eugenio Tello para aconsejar al respecto — su informe de 1889—, y la formulación de las primeras propuestas de arreglo entre las partes, que desarrollamos más abajo. Sin embargo, el asunto quedó en espera hasta la sentencia definitiva de 1906 que aseguró los derechos de propiedad privada de Alvarado en esas fincas. Lo curioso es que en las nuevas causas abiertas por este para formar los títulos de esas propiedades, en tres expedientes sucesivos ${ }^{40} \mathrm{se}$ advierte que se legitima su vieja pretensión de propiedad no por la compra efectuada oportunamente a Lozano, sino por ser heredero de Nemencio y Delfina Alvarado, sus padres. La justicia, en definitiva, sentenció desconociendo los derechos originarios de la merced Robles traspasados a Gordaliza, heredados por Lozano y adquiridos en compra por Tomás Alvarado, y reafirmó el carácter de despoblado, ocupados de hecho y prescripto por los progenitores de este último.

A su vez, para finales de la década de 1880 Tomás Alvarado realizó una serie de transacciones formalizadas pero que esconden negociaciones paralelas, algunas con fines especulativos. Efectivamente, en 1888 José Lozano le transfirió todos los remanentes de sus propiedades de Maíz Gordo y Santa Bárbara. El contrato se celebró sin mayores precisiones sobre superficies ni linderos salvo por el nombramiento que se hace de las fracciones vendidas previamente y sobre las cuales Alvarado no tenía atribución alguna. ${ }^{41}$ Aparentemente, el comprador fue apenas un intermediario del verdadero interesado de esta operación, el salteño Ángel M. Ovejero, a quien le traspasó Alvarado esos mismos derechos al año siguiente, en 1889. En ese nuevo contrato celebrado en la ciudad de Salta, Alvarado declara que el Dr. Ovejero era su socio en la operación de compras de aquellas propiedades y por tanto dueño de la mitad de ellas. ${ }^{42}$

40 Pie de la Cuesta y Campo Grande, San Salvador de Jujuy, 2 de septiembre de 1900, Archivo Histórico de Tribunales de Jujuy (AHTJ), expte. 476, año 1900; expte. 476 (continuación), año 1907 y expte. 476 (continuación), año 1909.

41 Embargo e inhibición de Maíz Gordo, Santa Bárbara y Este de la Totorilla, San Salvador de Jujuy, 5 de febrero de 1891, AHTJ, expte. 310, año 1891.

42 Nota oficial, San Salvador de Jujuy, 14 de enero de 1890, AHJ, Caja de Documentos, año 1890. 
Antes de sellarse este convenio hubo intentos de negociación previa entre Tomás Alvarado y el comisionado de los intereses públicos Eugenio Tello. El asunto nacía de la ambigüedad de los límites de esa última transferencia de Lozano a Alvarado, que se superponía con la delimitación de zonas fiscales que el Estado reconocía desde 1885 como «Tierras al Naciente» (zona 10 del mapa). ${ }^{43}$ Alvarado propuso entonces «donar» a la provincia la mitad de la superficie de tierras compradas a Lozano, a cambio de que esta desista sobre cualquier otro derecho dentro los límites concedidos en las mercedes de Robles e Iriarte. ${ }^{44}$ Tello aconsejó transar renunciando de este modo a una enorme extensión de tierras públicas, porque entendía que así se podía asegurar en forma eminente la propiedad para utilizar en garantía de crédito en la fundación de un banco oficial, comulgando con la filosofía liberal de «que las industrias se desarrollan en la tierra con derechos de propiedad claros, y no oscuros como hoy, por cuya razón esa zona no prospera»..$^{45}$

Como vimos, casi en el mismo instante se produjo la venta de Alvarado a Ovejero, sin que se concrete este pre-acuerdo. Pero, aparentemente, Alvarado desconocía que en su negociado con Ovejero se ocultaba un tercer socio, el gobierno de Jujuy. En los papeles oficiales se comenzó a tramitar, en 1890, la venta de todos los derechos y acciones de propiedad fiscal en Maíz Gordo y Santa Bárbara, sin mayor demarcación territorial, a la sociedad compuesta por Martín G. Guémez, Ángel M. Ovejero y José María Sanz (todos oriundos de Salta). La venta se selló el 11 de agosto de 1890, el precio fue de 101.750 pesos, en un contexto gubernativo forjado por la apremiante situación financiera pública a raíz del coletazo de la crisis de 1890, se buscaba «llenar el déficit de las rentas ordinarias y amortizar el préstamo de 100.000 pesos que contrajo con el gobierno nacional», y también «eliminar una inmemorable cuestión que perjudicaba a los pobladores de aquella región productiva por la indecisión en que se hayan sus derechos». ${ }^{46}$ Este convenio produjo bifurcaciones de diversos órdenes, en el corto y largo plazo.

43 Una superficie de 300 leguas cuadradas, que fueron declaradas fiscales por cuanto no habían sido incluidas como tierras de los Iriarte en los deslinde privados con Robles, ni habían comprendido las partes que vendieron los herederos de Robles a Gordaliza (Cuestiones de Límites, 1950, 139).

44 Carta de Tomás Alvarado de 1888 a Eugenio Tello, reproducida en Tello, 1889, 38.

45 Tello, 1889, 128-129.

46 Mensaje del Poder Ejecutivo de la Provincia, Jujuy, Tipografía de José Petruzzelli, 1891, 12. 
Por un lado, la venta de la propiedad pública de Santa Bárbara a la sociedad Ovejero, Guémez y Sanz fue rescindida cuando los entes fiscales descubrieron la oferta de esas tierras en remate, en un anuncio de negocios inmobiliarios de la prensa de Buenos Aires, publicado en enero de 1891. Se les trabó una orden de embargo e inhibición sobre la propiedad porque no habían cumplido con los pagos a la provincia de Jujuy estipulados en el contrato de venta ${ }^{47}$ Con aguda celeridad, en el mismo mes de 1891, se selló un acuerdo entre ambas partes por el que Ovejero y sus socios reconocieron como propiedad del estado jujeño esos terrenos fijando un límite conocido en lo sucesivo como «línea de transacción». Para rescindir el contrato de compra venta, Ovejero renunciaba a todos los derechos que pudiera tener por la compra hecha a Alvarado, con excepción de una parte determinada por esa divisoria y, a su vez, el gobierno de Jujuy renunciaba a cualquier pretensión de propiedad marcada por la misma línea de transacción. ${ }^{48}$ Para criterio de las autoridades provinciales ese resultado era muy favorable porque permitía que extensas zonas por fin quedaran reconocidas como fiscales y con límites definidos.

Por otro lado, la seguidilla de transferencias de las mismas tierras (la venta de Lozano a Alvarado, de este a Ovejero, de Ovejero al gobierno de Jujuy, de este último a Ovejero, Guémez y otros, y finalmente de estos tres de nuevo al gobierno de Jujuy) se reprodujo en un nuevo juicio que llegó a instancias de la Corte Suprema de Justicia. Mientras vivió Tomás Alvarado porfió sus derechos alegando fraude y manejos políticos. Denunció públicamente a Eugenio Tello como responsable de «combinación» en «consociedad» con Ángel Ovejero (refiriéndose a la venta efectuada por el gobierno de toda la tierra fiscal en la zona) para hacer retardar sus derechos de propiedad, cuando al mismo tiempo pactaron con él, ocultándole mayor información e incumpliendo con lo que se le había prometido:

que después de darse un trámite calculado para nunca resolver en este asunto, a pesar de no ser declaradas fiscales mis expresadas tierras [habla de Pie de la Cuesta y Campo Grande] en el informe del perito nombrado [...], dos sujetos altamente colocados de común acuerdo me dijeron que habían arreglado con el gobierno las cosas de tal manera que si yo condescendía en sus pretensiones todos los obstáculos creados para que yo no pueda disponer libremente de esas propiedades [...] desaparecerían. Las pretensiones era: que el uno le reconozca derechos como a cuatro leguas cuadradas de

47 Inhibición y embargo de Maíz Gordo, San Salvador de Jujuy, 15 de enero de 1891, AHTJ, expte. 301, año 1891.

48 Cuestiones de Límites, 1950, 228. 
mis tierras [...] compradas el 23 de noviembre de 1888 que [foja rota] en treinta mil pesos [foja rota] ${ }^{49}$ otro le regale quince mil pesos para salir de un apuro [...] accedí comprando así mi tranquilidad. ${ }^{50}$

A cambio, él desistió en la gestión de reconocimiento de propiedad de Pie de la Cuesta y Puesto Grande que tramitaba desde 1884, y luego vino la venta por parte del fisco a la sociedad de Ovejero. ${ }^{51}$

El punto final a los conflictos entre el gobierno de Jujuy y Tomás Alvarado trascendió su vida, marcando el cierre de una etapa en la definición de derechos de propiedad inaugurada desde la década de 1870 por las sucesivas acciones para reconocer tierra pública en Maíz Gordo y Santa Bárbara. El desenlace sucedió entre 1907 y 1911, tramo que duró la causa abierta por Felisa Torres de Alvarado (su viuda) en la Corte Suprema de Justicia, contra el Estado jujeño, caratulada como pedido de reivindicación de las tierras fiscales que eran de su propiedad, por nulidad e inconstitucionalidad de todos los decretos y leyes gubernativas obradas con anterioridad en este asunto. La reivindicación se hacía por la sexta parte que Tomás Alvarado se había reservado en la transferencia de las tierras compradas a Lozano a favor de Ángel Ovejero, y que este y sus socios luego transaron a favor de la provincia de Jujuy, porque Ovejero estaba inhabilitado para hacer esa cesión sobre derechos más extensos que los que le habían sido transmitidos en la operación con Alvarado. Otra razón de primer orden retomada en la sentencia era la inaceptabilidad según las pruebas aportadas de la caducidad de la merced de Robles por despueble, desconociendo en varios de los términos los conceptos de despoblamiento vertidos en la ley del 18 de diciembre de 1883. En congruencia con estos y otros puntos se declaró a la viuda de Alvarado y sus hijos con derechos absolutos a la porción comprada a Lozano y reservadas como propias en la cesión a Ovejero. ${ }^{52}$

En conclusión, el fallo de la Corte Suprema de Justicia reconoció derechos a favor de la sucesión de Tomás Alvarado no a una superficie territorial determinada ni inscrita geográficamente, sino a la sexta parte de las operaciones inmobiliarias entabladas entre Lozano-Alvarado-Ovejero y gobierno de Jujuy de finales de la década de 1880, una superficie estimativa. según

49 Haciendo alusión a la cesión que le hizo luego a Ovejero en 1889

50 Pie de la Cuesta y Campo Grande, San Salvador de Jujuy, 18 de julio de 1890, AHJ, Caja de Documentos, año 1890, expte. 120A, foja rota.

51 Recordemos que finalmente los derechos a esas fracciones le fueron reconocidos en 1906.

52 Reproducción parcial de la «Sentencia de la Corte Suprema de Justicia en la Nación en el juicio seguido por Doña Feliza Torres de Alvarado y otros contra la Provincia de Jujuy, 1911», en Cuestiones de Limites Interprovinciales, 1950, 240-241. 
el último deslinde existente de 1907, de 30.946 hectáreas a favor de los Alvarado. ${ }^{53}$ Quedaba pendiente esa labor (de reconocer in situ la propiedad reivindicada), que fue encomendada a Mario Romano. La obra abarcó distintas tareas: principalmente medir y amojonar el lote reivindicado a la sucesión Alvarado, establecer líneas demarcadoras de lindes interprovinciales y replantear la «línea de transacción» de 1891. Culminó en 1930 exigiendo rectificaciones de límites de propiedades particulares y fiscales, remoción de superficies territoriales de distintas fincas y resultando en nuevos recortes de medidas de las áreas fiscales. Era la consecuencia lógica del carácter de los derechos ejercidos en el medio siglo transcurrido desde la sanción de la ley de propiedad fiscal de Santa Bárbara de 1883, completamente enmarañados. ${ }^{54}$

Como vemos hasta acá el dominio público sobre las tierras de Santa Bárbara fue limitado a determinados puntos geográficos y fue sobre ellos que el Estado provincial pudo ejercer su administración. Las posibles operaciones que disponía la ley madre de 1883 era la venta con preferencia a ocupantes, programas de colonización y cesiones gratuitas. Lo más inmediato a esa declaratoria fue la «donación» hecha a Juan Pellischi en el año 1885 de unas 5.000 hectáreas. Por un pleito posterior entre ambos agentes (el señor Pellischi y el gobierno de Jujuy $)^{55}$ sabemos las motivaciones esgrimidas en la cesión de estas fracciones sin ningún tipo de condicionamiento al beneficiario, que no era vecino ni natural de la zona, sino un individuo con relativa participación en el Departamento Nacional de Ingenieros, de Buenos Aires. «Colocar tierras públicas» en personas emprendedoras para fomentar la inversión de capitales fue la doctrina perseguida en este caso, pero también retribuir con esta acción la campaña pública que oportunamente había emprendido Pellischi a favor del trazado de prolongación del ferrocarril central norte a Bolivia por Jujuy y la Quebrada de Humahuaca, que se disputaba con la provincia de Salta. ${ }^{56}$ En más de 20 años las tierras de Pellischi fueron infructíferas limitándose a lo producido por la renta de cuatro familias

53 Cuestiones de Límite, 1950, 271.

$54 \mathrm{Al}$ respecto dice el informe de Romano: «el perito pudo comprobar que la confusión de los límites entre los terrenos fiscales y los particulares era tal, que algunos que habían pagado pastajes al gobierno por la ocupación de terrenos [...], se habían negado a continuar haciéndolo o lo pagaban a otras personas que se creían con mejor derecho». Reproducción parcial del Informe del Perito Comisionado, Ing. Romano, de 1930, en Cuestiones de Límites Interprovinciales, 1950, 259.

55 Reclamo de dos leguas, San Salvador de Jujuy, 5 de septiembre de 1910, AHJ, Caja de Expedientes, expte. 93P.

56 Efectivamente el Ferrocarril a Bolivia podía tomar dos rutas alternativas transitando en su mayor parte geografía de la provincia de Salta o por la de Jujuy, suscitando un fuerte cruce de interés políticos que resultaron propicios para la segunda provincia (Bovi, 2013). 
arrendatarias, que en realidad ingresaron al fisco, en una muestra más de la permeabilidad que el ejercicio de la propiedad privada admitía. ${ }^{57}$

Además del intento fallido de transferencia de todas las tierras fiscales de Santa Bárbara y Maíz Gordo a la sociedad de Ovejero, la otra gran operación inmobiliaria que emprendió el Estado jujeño en estas tierras fue la concesión de tierras hecha a la compañía The Argentine Timber \& States, en 1906, de 50.000 hectáreas (un $27 \%$ de la propiedad fiscal contabilizada para esa época), por el valor de 40.000 pesos. El aval gubernativo que acompañó esta acción se fundamentó en el credo de que la tierra pública era un incentivo para atraer capitales y fomentar la radicación de empresas generadoras de riqueza, no solo privada sino también públicas. ${ }^{58}$ Efectivamente, la apuesta era la explotación de los bosques de la zona para fabricación de madera de construcción y elaboración del tanino, actividades que recobran un vuelo especial en la Argentina en ese momento. A su vez, el gobierno jujeño tenía claro que quería impedir una oleada especulativa con la activación de este mercado de tierras y que debía advertir los mecanismos para evitarla. Ese cometido hizo eco en el contrato con los capitales ingleses estableciendo una serie de condiciones previas antes de la escrituración definitiva de las tierras: un depósito de garantía de obras de 8.000 pesos y un reaseguro de inversión de 100.000 pesos que constate la radicación de la fábrica de tanino. ${ }^{59}$ Algunos testimonios refieren que había mejores ofertas de precios, que eran tierras que valían mucho más, por lo que seguramente el monto pagado fue uno de los beneficios de los inversionistas, a lo que se añadió la exención fiscal por 10 años.

La propiedad de la compañía inglesa radicada en Santa Bárbara encabezó la cúpula propietaria de la región durante las tres primeras décadas del siglo XX. El panorama de la estructura de la propiedad previo a la intervención del Estado sobre estas propiedades se modificó substancialmente para entonces. Según los datos que proporciona un catastro del año 1872 había solo 11 propietarios privados, siendo el de mayor fortuna el heredero

57 La provincia de Jujuy usufructuó de los arriendos fiscales de ese inmueble hasta el año 1909, fecha desde la cual «ninguno de estos arrendatarios han pagado al fisco porque se consideraron situados en tierras de propiedad particular, entre ellas algunas de las que pasaron a propiedad de Don Pedro A Prado». Reclamo de dos leguas, San Salvador de Jujuy, 5 de septiembre de 1910, AHJ, Caja de Expedientes, expte. 93P, f. 17v.

58 Mensaje del Gobernador de la Provincia de Jujuy Manuel Bertrés, año 1906, Jujuy, Imprenta de F. Wiaggio, (1906), 15.

59 Sesión ordinaria, San Salvador de Jujuy, 10 de enero de 1906, AHLJ, Actas manuscritas, 28 , fs. 124,125 y 128 . 
de la merced Robles, José Lozano, quién concentraba el $30 \%$ de la riqueza territorial. ${ }^{60}$ En cambio, en el año 1915 los dueños de tierras se habían quintuplicado en número (se catastraron 52), la compañía The Argentine Timber \& States reunía el mayor patrimonio, el $54 \%$ del valor inmobiliario total de Santa Bárbara, y solo tres de las familias propietarias de la década de 1870 perduraban en esa calidad (Gil, Gámez y Alvarado). ${ }^{61}$

\section{Una maraña de derechos II. ¿Y los ocupantes y pobladores?}

En Santa Bárbara existía un universo de pequeños criadores y productores agrícolas de auto-subsistencia quienes quedaron al margen del acceso a la propiedad privada durante la recirculación de la tierra promovida por el Estado provincial. Por las mismas condiciones ambientales y otras circunstancias, entre las pautas demográficas la región presentaba escasa densida$\mathrm{d},{ }^{62}$ muy poca población relativa ${ }^{63} \mathrm{y}$ una fuerte movilidad geográfica de sus residentes.$^{64}$ Además, el territorio prácticamente carecía de redes camineras y quedó fuera del trazado del ramal del Ferrocarril Central Norte que recorrió los valles subtropicales.

Con estas características, un problema inherente era la falta de mano de obra y la que había era cautivada por los establecimientos de gran envergadura (ingenios vecinos localizados en el departamento de San Pedro y Ledesma, las madereras y ferrocarriles). ${ }^{65}$ Las otras explotaciones

60 Catastro de las propiedades urbanas, rurales y enfitéuticas, 1872 y 1878, departamento San Pedro, AHJ, fs. 48-50, AHJ. No disponemos de datos estadísticos que inventaríen las propiedades en Jujuy en base a su extensión, contamos solo con los padrones levantados en diferentes años para el cobro de contribución territorial, que solo expresan los titulares y las valuaciones de las fincas.

61 Catastro Territorial de la Provincia de Jujuy, 1915-1917, departamento Santa Bárbara, AHJ, fs. 192-194.

62 En los informes de los deslindes consultados se advierte claramente la distancia que solía haber entre puntos con presencia humana y entre los pocos poblados existentes.

63 Alrededor del dos por ciento del total provincial entre mediados del siglo XIX y el año 1914.

64 También en los testimonios recogidos en los deslindes y juicios de mensuras se nota cómo esta población circulaba de una zona a otra asiduamente, ya sea dentro del propio departamento para asentarse según mas le conviniera, o emigraba a otros lugares en determinadas circunstancias.

65 En 1905 no se podía conseguir peones para operaciones de deslinde «en los demás lugares próximos; son despoblados, sin más habitantes que algunos puesteros que no pueden desatender la hacienda que cuidan, y algunos propietarios que si tienen peones, no los pueden ceder sin graves perjuicios. En el departamento de San Pedro, el más próximo al lugar de trabajo eran también escasos los brazos [...] los ingenios azucareros, la explotación de bosques, y los trabajos de prolongación del FC a Ledesma los absorbieron a todos». Deslinde y mensura de Quebrachal y Lecheronal, San Salvador de Jujuy, 25 de octubre de 1905, AHTJ, expte. 566, año 1905. 
económicas que se desarrollaron fueron la de ganadería bovina comercial - que se basada en un sistema de arriendo con puesteros-, y/o la producción agroganadera, principalmente de autosubsistencia. ${ }^{66}$ Tomando como indicador de ese paisaje social productivo la cría de ganado vacuno, según datos del censo económico de 1895 , vemos que cuatro de los 141 productores reunían el $20 \%$ de este ganado, más de 500 cabezas cada uno, mientras un $65 \%$ de ellos (91 criadores) congregaban el total de vacas de esos cuatro principales, correspondiente a otro $20 \%$ del stock total. Este último grupo tenía crías inferiores a las 100 cabezas, siendo más recurrentes aquellos con menos de 50 vacas per cápita. ${ }^{67}$

La organización de puestos era un modo típico de las grandes fincas, que facultaban a sus arrendatarios a trabajar como puesteros, requiriendo una prestación mínima al año y adquiriendo de este modo una cesión gratuita de tierra para la siembra de aprovechamiento individual; el beneficio también era para el propietario pues

el trabajo del arrendero en los grandes días de la faena ya sea en la cosecha o en la yerra, es indudable que representa una gran economía para el propietario, pues queda así el gasto de brazos limitados a esos días, pudiendo requerir durante el resto del año solo el trabajo de un hombre por legua, a sueldo, para distribución de las aguas cuidado, vigilancia o un número reducido de camperos, individuos encargados del cuidado de la hacienda en el monte. ${ }^{68}$

La confusión de derechos privados y públicos sobre determinados territorios, los largos pleitos, las propias dificultades geográficas y de recursos para un control estatal efectivo ${ }^{69}$ y la presencia de áreas sin poblamiento seguramente fueron factores propicios para el acceso a parcelas como ocupante de hecho o como puestero, dado que la tierra no se presentaba como un recurso escaso, sino en relativa disponibilidad y con pocas restricciones a estas formas de tenencia.

66 En un proyecto de ley de conchabo de 1892, que propone diferenciar a la población arrendataria con capacidad de costear la subsistencia familiar del que no para obligarlo a conchabarse se establece como mínimo de esa subsistencia el cultivo de cinco hectáreas y/o la posesión de cinco cabezas de ganado mayor o 300 menor. Proyecto de ley, San Salvador de Jujuy, 12 de enero de 1892, AHLJ, Caja de Documentos, 42, año 1892. El grueso de los productores de Santa Bárbara apenas alcanzaban ese límite.

67 Segundo Censo Nacional, año 1895, Cédulas censales, Archivo General de la Nación (AGN), legajo 180, Provincia de Jujuy, Boletín de ganadería, 30, Departamento de San Pedro, fs. 423-438.

68 Holmberg, 1988 [1904], 73.

69 La precariedad de la presencia estatal en la zona se constata en la carencia de la infraestructura mínima necesaria para funcionamiento de las agencias oficiales. Comisaría Santa Clara, San Salvador de Jujuy, 14 de febrero de 1911, AHJ, Caja de Expedientes, expte. 184LC. 
Esta idea se visualiza en las actas ofrecidas en el informe de mensura de Nicolás Alvarado de 1885, que toman nota de algunas de las prácticas vigentes por esa época. ${ }^{70}$ Por ejemplo, la trayectoria de un ocupante de hecho, que al poco tiempo se reconoce asimismo arrendatario y, finalmente, cubre obligaciones de propietario: «se estableció en este punto con treinta cabezas de ganado sin saber a quién pertenecían estos terrenos, que hace dos años tomó arriendos a don José R. Lozano considerándolo propietario de los mismos, que no obstante esto le han cobrado derecho territorial el año pasado». ${ }^{71}$

También la permisividad a la ocupación de hecho por parte de los sectores propietarios, que no ejercían mayores presiones rentísticas sobre residentes asentados en sus fincas, se visualiza en este otro testimonio: «hace como veintiséis años que se estableció en él [...] en el supuesto que estas tierras pertenecían a Lucas Gil, [...] que sin embargo de esto nunca le ha cobrado arriendos; que antes que poblara el declarante estos señores Gil tuvieron puesto de ganado en ese paraje, pero que lo retiraron». ${ }^{72}$

Poblador, poseedor, ocupante, propietario, puestero, arrendatario son los diversos estatus que revisten los testigos indagados por Nicolás Alvarado. En el rastreo hecho de estos sujetos en diferentes catastros de propiedad inmueble, un dato que salta a la vista es que la regla fue quedar al margen de la propiedad privada. La circulación de la tierra en Santa Bárbara se activó con nuevo ritmo desde que el Estado jujeño comenzó a intervenir para reconocer en este suelo tierra fiscal. Una vía de movilización del recurso provino de la oferta incentivada por los particulares, mediante el fraccionamiento privado de las grandes mercedes (como la que detentaban los herederos de Robles e Iriarte). Así, de nuestro cotejo sobre este universo de los residentes, puesteros, arrendatarios — salvando el caso de Eugenio Ruiz que había comprado en remate público la propiedad fiscal de Capichunco en $1865 ; 7^{73} \mathrm{y}$ los de Delfina Alvarado y Dámaso Salmoral que siendo pobladores pasaron a ser propietarios privados por prescripción de fracciones fiscales-, fueron unos cuantos arrendatarios de Lozano, quienes efectivamente pudieron comprar sus parcelas en uso.

70 Se labraron 64 actas que recogieron testimonios y declaraciones de casi 50 personas diferentes.

71 Alvarado, 1886, 61.

72 Ibidem, 64.

73 Estancia Potrero de Cachipunco, San Salvador de Jujuy, 6 de mayo de 1884, AHJ, Caja de Documentos, año 1884. 
Las operaciones inmobiliarias fraguadas sobre la amplia merced de Robles durante el siglo por su heredero José Lozano se transaron con distintos adquirientes. Algunas fueron celebradas con colindantes y otras en pago de servicios y amparos a los apoderados y abogados actuantes de las muchas tratativas judiciales en que se vio involucrado. ${ }^{74} \mathrm{Y}$ las que nos interesa subrayar se sellaron con algunos de sus arrendatarios y puesteros. $\mathrm{Si}$ damos crédito a un testimonio, para la década de 1880 José Lozano tenía previsto activar un mercado de tierras, fraccionando su inmensa propiedad para venderla entre los residentes afincados en ella. Pero, en cierto sentido, su plan se había coartado por la incertidumbre que provocó la declaratoria de tierra pública. ${ }^{75}$ Aun así algunos de sus arrendatarios pudieron concretar estas compras de tierras, constituyéndose en los únicos casos de toda Santa Bárbara que siguieron ese rumbo. ${ }^{76}$

En cuanto al Estado, el gobierno que inspiró la ley de tierra pública de 1883 también tenía en sus planes que los «poseedores» de estas tierras accedieran a la propiedad. Recordemos que esta ley estipulaba transferencias por cesiones para proyectos de colonización y/o gran inversión de capitales, y por venta prefiriendo los «actuales poseedores». En un decreto reglamentario posterior se reconoce como «poseedor» a todos los sujetos que detentaban diferentes formas de tenencia, con cualquier título de posesión, menos «los que han ocupado fracciones fiscales a nombre de otros en calidad de arrenderos hasta el 31 de diciembre de 1883, y que continúen como tales». De tal suerte, solo los primeros eran preferidos en las compra

74 Con este carácter pueden catalogarse las ventas que hizo a Lucas Rocha en 1883 (Cuestiones de Límites, 1950, 225), a Cosme Belaunde en 1865 (Información seguida por Cosme Belaunde, San Salvador de Jujuy, 7 de febrero de 1884, AHJ, Caja de Documentos, año 1884) y las distintas fracciones que transfirió a Tomás Alvarado.

75 «Todas las tierras de Santa Bárbara y Maíz Gordo han estado pobladas desde mucho tiempo atrás [...], pero se han despoblado, porque las autoridades principalmente, han hecho correr la vos de que iban a perder sus mejoras si reconocían por dueño a don José R. Lozano, porque el gobierno las iba a quitar y vender por fiscales de modo que siendo dudosa su posición y permanencia, para garantir su estabilidad las despoblaban: Que con la vos de que la tierras se iban a declarar fiscales, no se han venido estas tierras en fracciones en su mayor parte, como lo proyectaba el Sr. Lozano y aun los que ya habían dado a cuenta de compra se retractaron» (Alvarado, 1885, 28-30).

76 Los sujetos con este fortunio fueron Martín Graíño, Anacleto Báez, Cayetano Cruz, Francisco Farfán y José León Gallardo La historia personal de Francisco Farfán resulta una prueba de lo que pudo significar la experiencia de vida en estas tierras de Santa Bárbara. Él declara en un expediente donde oficia de testigo que fue desertor del ejército al mando de Alejandro Heredia cuando se desarrolló la Guerra contra la Confederación Peruano-boliviana (1837- 838), y que huyendo de la persecución fue que se asentó en la zona para esa época, ocupando un puesto de Gordaliza (Información seguida por Cosme Belaunde, San Salvador de Jujuy, 7 de febrero de 1884, AHJ, Caja de Documentos, año 1884, f. 9). 
y revestían el carácter de cuasi-propietarios ya que estaban comprendidos en los sujetos con obligación de pago de la contribución territorial. ${ }^{77}$

Iniciada la década de 1890 se nota un giro en la política del Estado para administrar estas tierras. Por un lado, se trató de vender en un solo paquete toda la propiedad fiscal de la región, según vimos en el negociado inicial con Ángel Ovejero y sus socios, desistiendo de los planteos iniciales de 1883 que preferían diferentes operaciones de menor escala con los «poseedores». Por otro lado, malograda esa venta se buscó racionalizar la tutela en el dominio de su patrimonio replanteando su visión sobre los «poseedores» de tierra fiscal, para establecerse claramente la figura de arrendatario del fisco. Fue así que: «Considerando que la clasificación de propietarios que por decreto del 11 de enero de 1884 se da a los poseedores de tierras fiscales de Maíz Gordo y Santa Bárbara, para el percibo de la contribución territorial que se le impone no corresponde a la designación que las leyes generales dan al propietario de bienes raíces, quedando a voluntad de ello eliminar el impuesto con tan solo mudarse de domicilio», se decretó que esos «tenedores» eran simples arrendatarios de bienes del Estado y se organizó el cobro del mismo por un valor de 20 pesos anuales por una legua cuadrada. ${ }^{78}$ Desde ese momento y hasta comienzos del siglo XX no hubo novedades en el manejo fiscal de estas tierras salvo por las múltiples acciones emprendidas para intervenir directamente en los arriendos. Su mayor atención se expresa, por ejemplo, en la elaboración de padrones específicos de arrendatarios ${ }^{79}$ inspecciones periódicas para reconocer «intrusos», cesión de arriendos y nuevas leyes. Aparentemente, la nueva figura de arriendo fiscal fue difícil de implantar en unos sujetos acostumbrados a «ocupar» sin más la tierra necesaria para su reproducción familiar, solían evadir el pago y su registro. ${ }^{80} \mathrm{El}$ gobierno logró un mayor control efectivo recién hacia mediados de la década de 1890 como resultado del esfuerzo seguido en el asunto ${ }^{81}$ sumando también desde ese

77 Decreto reglamentario, San Salvador de Jujuy, 11 de enero de 1884, AHJ, Registro Oficial, año 1884, fs. 277-278. Es por esa orden que en los padrones previos al año 1890 todos estos poseedores encabezan listas de propietarios para cobro de ese gravamen.

78 Decreto reglamentario, San Salvador de Jujuy, 16 de junio de 1892, AHJ, Registro Oficial, año 1892 , fs. $405-406$.

79 Arrendatarios de tierras fiscales, San Salvador de Jujuy, 13 de octubre de 1891, AHJ, Caja de Documentos, año 1891.

80 Decreto, San Salvador de Jujuy, 21 de febrero de 1894, AHJ, Registro Oficial, año 1894, f. 302 .

81 Mensaje del Gobernador de la Provincia, año 1895, Jujuy, Imprenta del Pueblo, (1895), 20. 
momento otras solicitudes de arriendos de sus tierras, amén de los que ya las ocupaban. ${ }^{82}$

La letra de los acuerdos de arriendos con el fisco revela que el principal uso productivo era el pastaje para ganado. Fue quizás ese factor por el que se introdujo una revisión en la modalidad de cobro, que a partir de 1903 se hacía no ya sobre la base de un monto por superficie de tierra sino en proporción al número de cabezas de ganado mayor o menor que cada uno poseía. ${ }^{83}$

Avanzando en la primera década de 1900 hubo un rediseño de las políticas sobre Santa Bárbara y Maíz Gordo que se plasmó en la nueva filosofía de venta por cesión a los capitalistas ingleses para el rubro maderero, como ya vimos; pero también en la sanción de una nueva ley de venta de tierras que introdujo, por primera vez en Santa Bárbara (aunque no en otros puntos geográficos donde se administraba propiedad pública), la modalidad del remate público. ${ }^{84}$

\section{Consideraciones finales}

El gobierno jujeño maniobró una serie de acciones durante el proceso de constitución de su patrimonio inmobiliario público afectando arraigadas legitimidades en las formas de control y de acceso a la propiedad de la tierra durante el siglo XIX. Si tempranamente la primicia fue desamortizar los bienes de la comunidad indígena concerniendo a sectores con menor capacidad de negociación en la relación de fuerzas, la novedad desde mediados del siglo XIX fue arremeter también sobre otras esferas más afanosas del poder: los intereses legatarios de algunas de las mercedes de tierras de origen colonial. El caso que tratamos de Santa Bárbara corresponde a esa segunda secuencia. En este trabajo se intentó clarificar y determinar cuáles y con qué fundamentos determinadas tierras fueron finalmente declaradas fiscales en Santa Bárbara reconstruyendo todo el periplo histórico entre mediados del siglo XIX y 1920.

82 Solicitudes de arriendos en tierras fiscales: San Salvador de Jujuy, 24 de julio de 1894, AHJ, Caja de Documentos, expte. 3475F; San Salvador de Jujuy, 16 de mayo de 1908, AHJ, Caja de Expedientes, expte. 1LY; San Salvador de Jujuy, 5 de noviembre de 1920, AHJ, Caja de Expedientes, expte. 23bis A; San Salvador de Jujuy, 30 de marzo de 1911, AHJ, Caja de Expedientes, expte. 16F.

83 Ley de arrendamientos, San Salvador de Jujuy, 3 de marzo de 1903, AHLJ, Caja de Documentos, 58-59, año 1903.

84 Sesión ordinaria, San Salvador de Jujuy, 13 de diciembre de 1905, AHLJ, Actas Legislativas, 28, f. 105 . 
Así, la fiscalización de tierras en Santa Bárbara resultó un largo proceso de legitimidad disputada, fue gradual (con marchas y contramarchas) tanto en los fundamentos, la reglamentación, como en la comprensión geográfica, abierta desde 1850 cerró un primer ciclo pasada la primera década del siglo XX. La declaratoria de áreas de propiedad pública fue progresiva, mientras por las propias desinteligencias del cuerpo político y los litigios desatados el reconocimiento legal de las mismas fue regresivo, reduciendo a la mitad la superficie inicialmente estimada.

La principal secuela fue la constitución de un mosaico de derechos sobre la tierra, añadidos y complejos. Un punto de inflexión de este dilatado proceso fue el deslinde las tierras practicado por Nicolás Alvarado en 1885, que hemos analizado en detalle. Como fruto del mismo se desencadenaron una serie de desacuerdos posteriores y un cúmulo de derechos inciertos afectando distintos intereses. Por un lado, los que se consideraban propietarios privados siguieron en ese credo, realizando contratos con tierras que el Estado reconoció como propias, a la vez que entablaron sucesivos pleitos. Por otro lado, a medida que se presentaron los problemas el Estado fue desmembrando partes de las tierras públicas, especulando en diversas transacciones, difiriendo resoluciones y también privatizando algunas porciones. Finalmente, los pobladores se auto-consideraron y fueron reconocidos alternativamente, a veces simples ocupantes, otras veces propietarios y definitivamente arrendatarios.

El desmembramiento de los terrenos fiscales fue una consecuencia de las pérdidas a favor de la jurisdicción de Salta y sus vecinos por conflictos limítrofes, la recomposición de límites con los propietarios privados de la zona y las ocupaciones de hecho que buscaban posesión por prescripción. De todos modos, se llegó a constituir un patrimonio de más de 180.000 hectáreas.

¿Qué hizo el gobierno de Jujuy con las que estuvieron a su alcance? Celebró contratos de arrendamiento y transacciones de venta y de concesión. Puso su mayor esfuerzo en promover la radicación de los capitales externos en inmuebles y la iniciación de la actividad forestal local en gran escala, por ejemplo a través del establecimiento de The Argentine Timber \& Estates Company Limited, congruente con la forma en que sus plataformas políticas entendían el «progreso». Pero en el proceso se fue rescindiendo el afán de facilitar el acceso a los puesteros, criadores de algún ganado y pequeños productores agrícolas que componían la fotografía de la población avecindada en Santa Bárbara. Por el contrario, de ese espectro de actores 
los pocos que devinieron en propietarios de tierras, las adquirieron no del Estado sino del bastión privado de José Lozano. Y el resto fue mutando su estatus de ocupantes con prioridad de derechos de propiedad al de simples arrendatarios.

Recibido el 6 de marzo de 2015 Segunda versión el 21 de septiembre de 2015 Aceptado el 5 de noviembre de 2015

\section{Referencias bibliográficas}

Alvarado, Nicolás, Provincia de Jujuy. Deslinde las tierras fiscales de Santa Bárbara y Maíz Gordo, Jujuy, Imprenta de La Unión de P. Sarapura, 1886.

Blanco, Graciela y Banzato, Guillermo (comps.), La cuestión de la tierra pública en Argentina. A 90 años de la obra de Miguel Ángel Cárcano, Rosario, Prohistoria, 2009.

Bovi, María Teresa, «El Ferrocarril Central Norte y su prolongación a Bolivia. Estado, elites provinciales y los discursos sobre la modernidad», en Cicerchia, Ricardo, Caminos de fierro. Tren a Bolivia. El ramal San Salvador de Jujuy-La Quiaca en la primera mitad del siglo XX, Rosario, Prohistoria, 2013, 79-100.

Cárcano, Miguel Ángel, Evolución histórica del régimen de la tierra pública 18101916, Buenos Aires, Eudeba, 1972.

Cuestiones de Límites Interprovinciales, Litigio Jurisdiccional entre las provincias de Salta y Jujuy (Zona I), Antecedentes, Buenos Aires, Dirección Provincial del Instituto Geográfico Militar, 1950.

Fandos, Cecilia, "Los "sagrados derechos" en cuestión. El conflicto por la tierra en las haciendas de la Quebrada de Humahuaca (Jujuy, Argentina), décadas de 1870 y 1880», Revista Andes, 26, Salta, 2015, 1-25.

Fandos, Cecilia y Teruel, Ana, «La compra-venta de tierra fiscal y los procesos de "perfeccionamiento" de la propiedad en Quebrada de Humahuaca. Provincia de Jujuy (1860-1922)», en Banzato, Guillermo (ed.), Tierras rurales, políticas, transacciones y mercados durante el siglo XIX en la Argentina, Rosario, Prohistoria, 2013, 149-1776.

Holmberg, Eduardo A., Investigación agrícola en la provincia de Jujuy, Jujuy, Universidad Nacional de Jujuy, 1988 [1904].

Madrazo, Guillermo, Hacienda y encomienda en los Andes. La Puna de Jujuy bajo el marquesado de Tojo, siglos XVII-XIX, Buenos Aires, Fondo Editorial, 1982.

Míguez, Eduardo, «Los condicionantes del proceso de apropiación de tierras en el Río de La Plata en el siglo XIX en perspectiva comparada: naturaleza, 
mercados, instituciones y mentalidades», Revista de Instituciones, Ideas y Mercados, 47, Buenos Aires, 2007, 117-150.

Paz, Gustavo L., «Hacienda, encomienda y orden rural en el Norte argentino, Jujuy, 1850-1900», Anuario de Estudios Americanos, 61-2, Sevilla, 2004, 551-570.

Segundo Censo de la República Argentina de 1895, Tomo II, «Población», Buenos Aires, Taller Tipográfico de la Penitenciaría Nacional, 1898.

Tello, Eugenio, Provincia de Jujuy. Informe del comisionado especial Eugenio Tello sobre las tierras de Maíz Gordo, Santa Bárbara y Este de la Totorilla, Buenos Aires, Imprenta La Nación, 1889.

Tercer Censo Nacional de 1914, Tomo II, «Población», Buenos Aires, Talleres Gráficos de L.J. Rosso y Cía., 1916.

Teruel, Ana y Bovi, María Teresa, «El ordenamiento de la propiedad territorial en Jujuy. Del "antiguo régimen" a la "modernidad"», en Teruel, Ana A. (dir.), Problemas nacionales en escalas locales. Instituciones, actores y prácticas de la modernidad en Jujuy, Rosario, Prohistoria, 2010, 93-124.

Teruel, Ana, Misiones, economía y sociedad. La frontera chaqueña del Noroeste Argentino en el siglo XIX, Buenos Aires, Universidad Nacional de Quilmes, 2005.

Uriondo Tochón, Eduardo, Límites interprovinciales. Teoría general, Cuestión Jujuy-Salta, Jujuy, Imprenta del Estado, 1966. 


\section{Anexo}

\section{TABLA I. DEPARTAMENTO DE SANTA BÁRBARA. CLASIFICACIÓN DE DERECHOS DE PROPIEDAD SEGÚN EL DESLINDE Y MENSURA DE NICOLÁS ALVARADO, 1885}

\begin{tabular}{|c|c|c|c|c|}
\hline Zona & Nombre de la Finca & Clase & Fundamentación & Forma de tenencia \\
\hline I & Lavayen & Fiscal & $\begin{array}{l}\text { Imprecisión de } \\
\text { linderos. Insuficiencia } \\
\text { y carencia de } \\
\text { títulos auténticos de } \\
\text { poseedores actuales }\end{array}$ & Poseedores \\
\hline II & Este de Totorilla & $\begin{array}{l}\text { Fiscal } \\
\text { Privatizada }\end{array}$ & $\begin{array}{l}\text { Fiscales } 1876 \text { (una } \\
\text { parte). Despobladas } \\
\text { en } 1885 \text { (en } \\
\text { sobrantes de tierras } \\
\text { no comprendidas } \\
\text { en ninguna merced } \\
\text { originaria) }\end{array}$ & $\begin{array}{l}\text { Propiedad privada } \\
\text { Anacleto Corro } \\
\text { (compradas al fisco en } \\
1876 \text { ) }\end{array}$ \\
\hline III & Cachipunco & $\begin{array}{l}\text { Fiscal } \\
\text { Privatizada }\end{array}$ & Fiscal desde 1863 & $\begin{array}{l}\text { Propiedad privada } \\
\text { Eugenio Ruiz } \\
\text { (compradas al fisco en } \\
1865 \text { ) }\end{array}$ \\
\hline IV & $\begin{array}{l}\text { El Quemado } \\
\text { Gramillar } \\
\text { Palmar } 50\end{array}$ & Fiscal & $\begin{array}{l}\text { Despobladas } \\
\text { Insuficiencia y } \\
\text { carencia de títulos } \\
\text { auténticos de } \\
\text { poseedores actuales }\end{array}$ & $\begin{array}{l}\text { Poseedores (compradas } \\
\text { a José Lozano) }\end{array}$ \\
\hline V & $\begin{array}{l}\text { Algarrobal y Potrero Santa } \\
\text { Rita. Vinalito, Agua Dulce, } \\
\text { Palmar, Palos Blancos y } \\
\text { Hoyada Vieja, Saladillo }\end{array}$ & Fiscal & $\begin{array}{l}\text { Imprecisión de } \\
\text { linderos } \\
\text { Carencia de título }\end{array}$ & $\begin{array}{l}\text { Poseedor } \\
\text { Villar, Salvador }\end{array}$ \\
\hline VI & $\begin{array}{l}\text { Agua Caliente } \\
\text { Laguna de Brea } \\
\text { La Quinta }\end{array}$ & Fiscales & $\begin{array}{l}\text { Insuficiencia de títulos } \\
\text { Despoblados (partes } \\
\text { sobrantes de propiedad } \\
\text { privada) }\end{array}$ & Poseedores \\
\hline VII & Totoral y Chacarita & Sin definir & $\begin{array}{l}\text { Sin comprobación de } \\
\text { derechos }\end{array}$ & Poseedores \\
\hline VIII & $\begin{array}{l}\text { Quebrachal } \\
\text { Lecheronal }\end{array}$ & Sin definir & $\begin{array}{l}\text { Sin comprobación de } \\
\text { derechos }\end{array}$ & $\begin{array}{l}\text { Poseedores } \\
\text { José y Tomás Gámez }\end{array}$ \\
\hline IX & $\begin{array}{l}\text { Alto de la Victoria y } \\
\text { Manguita, Piquete y Santa } \\
\text { Clara }\end{array}$ & Sin definir & $\begin{array}{l}\text { Poseedores no se } \\
\text { presentaron al deslinde }\end{array}$ & Poseedores \\
\hline
\end{tabular}




\section{CECILIA A. FANDOS}

\begin{tabular}{|c|c|c|c|c|}
\hline Zona & Nombre de la Finca & Clase & Fundamentación & Forma de tenencia \\
\hline $\mathrm{X}$ & Sin parajes reconocidos ${ }^{85}$ & Fiscales & Despobladas & Sin ocupantes \\
\hline XI A & $\begin{array}{l}\text { Merced Robles } \\
\text { Transferidas a Gordaliza/ } \\
\text { Lozano }^{86}\end{array}$ & Privadas & $\begin{array}{l}\text { Poblados con } \\
\text { anterioridad a 1850, } \\
\text { según información de } \\
\text { testigos }\end{array}$ & $\begin{array}{l}\text { Propiedad privada de } \\
\text { José Lozano. } \\
\text { Pobladas con } \\
\text { arrendatarios de Lozano }\end{array}$ \\
\hline XI B & $\begin{array}{l}\text { Merced Robles } \\
\text { Transferidas a Gordaliza/ } \\
\text { Lozano: } \\
\text { San Rafael, Isla y Avispas, } \\
\text { Chancacas y Lanza, Agua } \\
\text { Negra, Quebracho, Arroyo } \\
\text { Colorado }\end{array}$ & Privado & $\begin{array}{l}\text { Parcelas vendidas por } \\
\text { José Lozano }\end{array}$ & Propietarios privados \\
\hline XI C & $\begin{array}{l}\text { Merced Robles } \\
\text { Transferidas a Gordaliza/ } \\
\text { Lozano: } \\
\text { Isla Grande, Quebrachal, } \\
\text { Saladillo, Santa Fe, } \\
\text { Lapachal, Chuschal }\end{array}$ & Fiscales & $\begin{array}{l}\text { Despobladas antes } \\
\text { de } 1850 \text { y ocupadas } \\
\text { recientemente }\end{array}$ & $\begin{array}{l}\text { Ocupantes/Poseedores. } \\
\text { Arrendatario de Lozano }\end{array}$ \\
\hline XI D & $\begin{array}{l}\text { Merced Robles } \\
\text { Transferidas a Gordaliza/ } \\
\text { Lozano: } \\
\text { Real de los Toros, Palmitas, } \\
\text { Pie de la Cuesta y Campo } \\
\text { Grande. Puesto Grande, } \\
\text { Maíz Gordo, Mealla El } \\
\text { Chorro, Arenal, Agua } \\
\text { Hedionda }\end{array}$ & Indefinido $^{87}$ & $\begin{array}{l}\text { Dudas sobre la } \\
\text { veracidad de la } \\
\text { declaración de los } \\
\text { ocupantes }\end{array}$ & $\begin{array}{l}\text { Ocupantes/poseedores. } \\
\text { Puesteros }\end{array}$ \\
\hline
\end{tabular}

85 Tierras de Maíz Gordo en el extremo sureste de Santa Bárbara (lindante con Salta).

86 En 1813 la sección de la merced de tierras de Francisco Javier Robles que este había reservado para herencia de sus hijas, fue vendida por dichas sucesoras a Mariano Gordaliza. En 1855 fue declarado y reconocido con registro de escribano como heredero universal de esas tierras José R. Lozano, de cuyo dominio se resolvieron como fiscales algunas fracciones en la década de 1880. Alvarado, 1886,126 y 130.

87 Estuvieron sujetas a una circunstancia especial a la muerte de Gordaliza (robo de ganado y ocupación ilegítima). 